\title{
HOW DO PEOPLE SEEKING ASYLUM IN THE UNITED KINGDOM CONCEPTUALISE \& COPE WITH THE ASYLUM JOURNEY?
}

\author{
Thomas Hoare $^{1}$, Andrew Vidgen ${ }^{2}$ \& Neil P. Roberts ${ }^{3,4}$ \\ 1Child \& Family Psychology Department, Aneurin Bevan University Health Board, UK; 2Rehabilitation and \\ Recovery Service, Adult Mental Health Services, Cardiff and Vale UHB, Cardiff, UK; 3Traumatic Stress Service, \\ Cardiff and Vale UHB, Cardiff, UK, 4Division of Psychological Medicine and Clinical Neurosciences, Cardiff \\ University, Cardiff, UK.
}

\section{Notes on Contributors}

Dr Thomas Hoare - Clinical Psychologist at Aneurin Bevan University Health Board. Previously worked in Forensic Mental Health Services, and for an International Non-Governmental Organization establishing mental health programs overseas (including Nigeria, Ethiopia, Myanmar, Syria and Turkey). Email: Thomas.hoare@wales.nhs.uk ORCID iD: 0000-0003-2227-294X

Dr Andrew Vidgen - Consultant Clinical Psychologist, Recovery Services, Cardiff and Vale University Health Board. Clinical and research interests are in the clinical application of values, displaced migrants, psychosis and supervision.

Dr Neil Roberts - Consultant Clinical Psychologist with Cardiff and Vale University Health Board and Honorary Senior Research Fellow with the Division of Psychological Medicine and Clinical Neurosciences, Cardiff University. Research interests are related to the investigation and evaluation of psychological interventions for PTSD.

\section{Disclosure Statement}

No potential conflict of interest was expressed by the authors. 


\begin{abstract}
People seeking asylum experience traumatic events and psychological difficulties in country-of-origin, in 'flight', and during re-settlement. Research with this population has focussed on using quantitative methods to examine psychopathology from exposure to traumatic events, and there is a paucity of qualitative research exploring subjective experiences of this population throughout their asylum journey. Few studies have examined ways asylum seekers might cope with such events. This study aimed to address this gap by employing Constructivist Grounded Theory to understand the ways people seeking asylum conceptualise and cope with their experiences across the asylum process. Semi-structured interviews were conducted with eleven people seeking asylum accessing a third sector mental health project and / or primary-care health service. Four main themes emerged from the data: 'Before Asylum', 'Displacement', 'Identity in the UK' and 'Reflections on the Future'. The stress of the asylum system and adaptation to new environments are core aspects of the theory, along with an exploration of how people cope with these circumstances, via internal psychological strategies and external support sources. Prior experiences (including the development of 'inner strength') impacted upon how participants conceptualised their everyday experiences, and this shaped their considerations for the future. Service implications are discussed.
\end{abstract}

Keywords: asylum seeker; constructivist grounded theory; qualitative research 


\section{Introduction}

An 'asylum seeker' is someone who has made a claim under the 1951 Convention Relating to the Status of Refugees (United Nations, 1951) and is awaiting a decision on their case. That person remains an asylum seeker for so long as their application is pending (Migration Watch UK, 2006). A minority of applicants gain permission to stay in the UK ('leave to remain') which may mean official recognition as a refugee (permission to stay for 'humanitarian protection'), through 'discretionary leave to remain' (permitting five-year residency), following which a person/family can applying for 'indefinite leave to remain' (Blinder, 2016). If unsuccessful, the asylum seeker can appeal, but is technically a 'refused' asylum seeker and could potentially be removed to their country-of-origin.

The residency and legal status of individuals who are seeking asylum is in a continuous state of flux (Stewart, 2005), and consequently, some studies have labelled the population 'forced migrants' (e.g. Palmer \& Ward, 2006) indicating that participants may be either asylum seekers or refugees. This paper utilises this terminology, unless 'asylum seeker' or 'refugee' is specifically stated.

According to Migration Watch UK (2017) there were an estimated 245,000 applications (excluding dependent family members) for asylum in the UK between 2007 and 2017. Of these, approximately $40 \%$ were granted refugee status. The number of asylum applications to the UK has dropped from 84,132 (2002) to 29,380 (2018), and in 2018, $67 \%$ of applications were refused at initial decision (House of Commons Library, 2019).

The Home Office have a six-month target for processing applications, though this can take considerably longer (House of Commons Library, 2019). Refugee \& Asylum Seeker Voice (2017) highlight that asylum seekers do not have the right to work in the UK and rely on minimal state financial support (often via provision of vouchers that are limited to certain goods and outlets). Housing is provided, but asylum seekers cannot choose where to live, and may be placed in any UK area. People who have made applications and have had their claim refused are entitled 
to similar rights as person's whose claim is in progress, though support can be stopped unless a person is in exceptional circumstances, and, as mentioned, this group are at increased risk of being detained and / or removed.

Public attitudes towards asylum seekers in the UK are often hostile (e.g. Nissa, 2005) and such beliefs are often exacerbated by sections of the media (Pearce \& Charman, 2011). An analysis of a number of European newspapers, taking into consideration the number of rejected asylum claims, and difficulties in accessing social, health and employment, has labelled the UK as 'one of the worst places in Western Europe for asylum seekers' (Lyons et. al., 2017). In some cases, it can take considerable periods of time for the Home Office to grant an applicant asylum support which can lead to tragic consequences, including homelessness (Refugee \& Asylum Seeker Voice, 2017). It is further suggested that the UK Government adopting of a 'hostile environment' policy (a range of measures driven by the UK Government Immigration Act $(2014,2016)$ to reduce the number of immigrants in the UK) has exacerbated social and economic difficulties for those seeking asylum (Taylor, 2018).

Research literature pertaining to psychological wellbeing amongst forced migrants has generally focussed on using quantitative methodologies to examine psychopathological reactions (e.g. PTSD, anxiety, depression) to events experienced by this population, which highlight higher incidence of such problems (e.g. Carey-Wood et al., 1995, Onyut et al., 2009; Priebe, Giacco \& El-Nagib, 2016;). This is perhaps unsurprising given that forced migrants are more likely to have had exposure to a range of known risk-factors for developing mental health problems, in countryof-origin, in-flight, and in resettlement (Van de Veer, 1998). Studies have indicated that forced migrants affected by war and human rights violations report an average of 7-15 traumatic events per person (e.g. Mollica et al., 1998), and torture is reported by as many as $54 \%$ of respondents (e.g. Marshall et al., 2005). Some studies have suggested that increased psychopathology is associated with post-migratory factors (Carswell, Blackburn \& Barker, 2011), including delays in the asylum application process and poor socio-economic living conditions (Laban et al., 2005; Silove et al., 1997; Steel et al., 1999), detention (Steel et al., 2006) and reduced social support 
(Schweitzer, Greenslade \& Kagee, 2007). Other researchers critique the use of a PTSD framework due to the distinction between past and present traumatic events, and the cultural applicability of such a diagnosis (Afuape, 2011; Summerfield, 2001). Further models highlight the importance of acceptance from the community to promote recovery (Herman, 1992), attachment theory in understanding trauma-reactions (de Zulueta, 2007), and resilience (Bonnano, 2004; Schweitzer, Greennslade \& Kagee, 2007).

A review of the literature pertaining to subjective experiences of forced migrants using qualitative methodologies yielded a small number of results (Hoare, Vidgen \& Roberts, 2018), though the authors acknowledged that a limitation of this study was exclusion of 'grey literature' (e.g. reports by charities, dissertations etc.) and were limited to published academic studies in the English language). Some studies explored particular aspect of the asylum seeker journey, such as destination choices (e.g. Zimmermann, 2009), experiences of detention (e.g. Coffee et al., 2010), Home-Office asylum interviews (Bogner, Brewin \& Herily, 2010) or the impact of an uncertain asylum status on females (e.g. Rees, 2003). Other studies explore psychological distress and / or wellbeing in forced migrants (e.g. Renner \& Salem, 2009; Palmer \& Ward, 2007; Whittaker et al., 2005). A small number of qualitative studies focused on the cultural identity of forced migrants (e.g. O’Sullivan-Lago et al., 2008; 2010; Pearce \& Charman, 2011; Conlon, 2011; Rugunanan \& Smit, 2011) or social welfare, housing and employment issues for forced migrants (e.g. Hussein et al., 2011; Dwyer, 2005; Dwyer \& Brown, 2005). However, what was clear in the review is that the asylum process itself, as well as responses to those seeking asylum in the UK, contribute to psychological distress.

Hoare, Vidgen \& Roberts (2018) found no studies that focused on the asylum process from displacement to securing asylum in the host country. However, given that the search for this review was conducted in 2013, a further search was conducted in 2020 to ascertain whether there had been any further publications (adhering to the same inclusion and exclusion criteria) in the interim. Whilst a small number of studies were identified examining asylum seeker experiences of psychological therapy (Vincent et. al. 2012), expectations and trust of primary care services 
(O'Donnell et. al. 2008) and access to services (Kang, Tomkow \& Farrington, 2019), and the links between housing and health (Ziersch et. al., 2017), similarly to Hoare, Vidgen and Roberts (2018), no identified studies focused on the experiences of asylum seekers throughout the asylum process.

\section{Aims}

Given the specific issues faced by asylum seekers and potential psychological sequelae, the aim of the current study was to investigate experiences of the asylum journey alongside methods of coping. In order to do this an established qualitative approach, Constructivist Grounded Theory (CGT; Charmaz, 2006) was employed to deepen the understanding of people's experiences whilst seeking asylum.

\section{Materials and Methods}

\section{Design}

The study utilised a qualitative methodology guided by the principles of CGT, defined as being a method that creates a framework through inductive analysis of interview data, grounded in participant narratives, which actively involves the researcher in co-constructing such narratives (Charmaz, 2006). Other qualitative approaches (e.g. thematic analysis) were considered, though the researchers wanted to enable multiple perspectives from participants to be drawn together in an overall theoretical conceptualisation, and CGT was chosen because it allows for this (Charmaz, 2006).

\section{Ensuring Quality}

Guidelines developed by Elliot et. al. (1999) were employed to ensure credibility, reliability and quality-control, i.e., clearly state the position of the researchers, and provide demographic information for the reader to understand participant characteristics. These 
guidelines are broadly similar in nature to the COREQ (Consolidated criteria for reporting qualitative research) standards, which are widely used to ensure standards in qualitative research (Tong, Sainsbury \& Craig, 2007). As noted by Charmaz (1995), a 'position of self' is necessary for readers to understand the researcher perspective and subject data to appropriate critique. The primary researcher positions himself as a male psychologist holding strong beliefs regarding social justice and universal human rights.

\section{Participants}

Following NHS Ethical and Research and Development (R\&D) approval, eleven people seeking asylum in the UK from the Middle East, Southern Asia and Central Africa were recruited via a third sector BAME (Black, Asian \& Minority Ethnic) mental health support service and /or NHS Primary Care service in South Wales. It was decided for practical purposes (e.g. interpretation costs) to focus on asylum seekers who could speak a particular language, and recruiting organisations suggested that the population that would be most accessible for the study were Farsi-speaking people from the Middle East. A Farsi- and English-speaking interpreter was used with the majority of interviews (except where participants could speak English). Information sheets were developed in both languages. To be included in the study, participants had to be actively seeking asylum and awaiting an outcome on their asylum decision, speak English and / or Farsi, be over 18 years old, and have capacity to consent to interview.

Participants had an average age of 38 years and had been in the UK for a mean of 18.5 months. Seven participants were male and four female. Nine participants were from the Middle East, one from Southern Asia, and one from Central Africa. Demographic information about participants is presented in Table 1. In order to maintain confidentiality, all names were changed, and demographic information presented in terms of ranges, as opposed to specific identifiers.

\section{INSERT TABLE 1 HERE}

\section{Procedure}


Information sheets and consent forms (developed using British Psychological Society guidelines $(2009 ; 2011)$ and the Data Protection Act (1998)) were completed with participants. Semi-structured interviews were used to elicit information about the ways that people seeking asylum in the UK experience the asylum journey and process of seeking asylum, with an emphasis on how people coped with such experiences. Initially, the interview schedule was broad in nature, having been developed by the research team in collaboration with recruiting organisations who had experience of working with this population. However, as interviews progressed, the schedule was revised to respond to emerging data, consistent with a CGT methodology.

\section{Data Analysis}

Data from audio-recordings of interviews was transcribed by the primary researcher (first author). The process of CGT involves initial line-by-line coding followed by focussedcoding, memo-writing, categorisation and 'triangulation', all of which occur simultaneously to enable the researcher to ground the theory in the data (Willig, 2008). Having a sample of 10-12 participants is considered sufficient to conduct this type of qualitative research (Dey, 1999; Charmaz, 2006).

\section{Results}

Four key themes emerged from the data, as shown by the CGT illustrated in Figure 1. This longitudinal theory developed linear narratives described by participants, highlighting different stages of the asylum journey, including the impact of the asylum system, stressors in adapting to a new environment, and the ways in which they coped. Each aspect of the theory is described and illustrated by quotes from participants to ensure that the theory was grounded in the data.

\section{INSERT FIG 1 HERE}

\section{Theme 1: Before Asylum}


Participants described pre-asylum circumstances in their home country as being indicative of a 'good life' marked by financial, familial and employment security. Participants discussed aspects of their lives which had helped develop resilience through strong family bonds and cultural identity, or conversely, via confrontation with adverse situations.

\section{A Good Life}

Prior to events which forced participants into having to leave their country of origin, many described having positive life experiences, often characterised by having secure employment, financial prosperity and being closely connected to family and friends. Here Suri speaks to the misconception that people seeking asylum are doing so for economic reasons. "Most people who come here are not coming because of financial things...they have all had their own education and had good finances [at home]." (Suri)

Ferhad, makes the comparison about what he left behind, and the downturn of fortunes.

"Coming from a wealthy... loving family around me, I didn't have anything which I wanted and dreamed for...when I think about [home], I had a really good time, compared to now." (Ferhad)

\section{Inner Strength}

Many participants described a process of developing 'inner strength', a notion which best-captured the concept of resilience in their life pre-migration, which had helped them to cope with subsequent difficulties as asylum seekers. The basis for the development of inner strength was broad, and spanned experiences earlier in life that could be considered positive and supportive, although in some cases, more challenging. Here, Ferhad speaks of the history of his 'race' and their ongoing struggle for basic human rights; though as always being strong. Saeed also speaks of his personal history and how difficult experiences have prepared him for his current challenges.

"We are a strong race...for thousands of years...We are looking for rights, and...not giving up... With all those pressures coming at us, we have the power to keep our language, to keep our cultures, clothing, customs." (Ferhad)

"I've had a difficult life. I was in the war... and in prison a couple of times because of political problems...we have a phrase; I was raw and now I've been cooked...In a way because of 
difficulties, it's easier for me to deal with daily problems...they say I have the skin of a rhino." (Saeed)

\section{Theme 2: Displacement}

Whilst talking about their previous life, participants went on to outline reasons why they had decided to leave their country-of-origin. All had 'encountered difficulty' around key events (a 'falling out' with religious, political or familial systems) that sometimes resulted in experiences of trauma and torture. This forced participants from a stable life into insecurity, danger and a need for safety. All participants had embarked on lengthy and challenging journeys to the UK and had arrived in a state of distress, disorientation and a carrying a strong sense of loss related to their previous lives.

Deciding to Move

To differing extents, all participants experienced events which had shifted their position from having a 'good life', to that of being under threat by family, religious or political authorities in the person's home country, as illustrated by the narratives of Thomas and Niki:

"I was defending people who were claiming their rights at work...I was accused of supporting those people." (Thomas)

"I hid three people [who] had attended an anti-government demonstration... when the government found out, they said that I was involved and arrested me...I lost my job when I was released...I didn't want to put myself in any more risk. So I...ran away." (Niki)

As a result of such difficulties, some participants described being arrested and detained by authorities, and were often subject to torture and abuse. Ahmed, for example, described some of the traumatic events that he was exposed to, and it subsequently became clear that he had not had the opportunity to discuss such events with anyone (perhaps evidencing the well-documented need for someone to 'bear witness' to their trauma). Such traumas can lead to a person's confrontation with their own mortality and questioning of their ability to survive.

"You haven't seen those nails in front of your eyes...You haven't felt the [mock] execution feeling. I went through all of these things when I was in prison. Every day, they took me to the execution room. I could see the hanging things on the roof of the ceiling. You haven't been in the room with only death staring at you...They hit me for half an hour a day"(Ahmad) 
As a consequence of such events, participants described an urgent need to escape their country. Some, including Farid and Siddiq, described the need to seek safety as the most important factor in their asylum journey, despite at times not wanted to leave their country-of-origin;

"I came here just because my life was in danger...we have loads of problems in [my country] so people come...for real good reasons. Safety reasons". (Farid)

"It is very difficult to leave your home [and] your friends [and] your family [and] your culture. And if someone is doing that, someone should think that maybe he is having a problem, that is why he is trying to seek asylum." (Siddiq)

Travel to the UK \& Arrival

Many participants described their journey to the UK, the majority of whom used expensive agents/smugglers to help them escape via other countries, which at times presented further challenges, including detention, leading to further traumatisation. Here, Majid gives an impression of the extent to which they had gone to escape his home country, and how distressing this journey had been;

"[for] 18 days I was on the way here, I changed a couple of lorries...I was so tired...Those last three days [of the journey] when I was being transported in a fridge...there were three of us, just trying to keep each other warm...it was just lettuce [in the fridge], so at least it was something that we could eat, to give us some energy...just to survive." (Majid)

\section{Arrival in the UK}

On arrival in the UK, many participants described the asylum application process, and whilst in some cases there were positive interactions with authorities, most suggested that this involved predominantly challenging encounters with UK immigration, detention centres, and the police, including the threat of removal as illustrated by Ferhad;

"When I came here they took me to a detention centre...they said that I didn't have any rights in the UK, and that I had to be deported...policemen came into my room and...handcuffed me. It was really bad...tight... They behaved like I was a terrorist...they wrapped me with a belt. So I couldn't speak...I was trying to say that my handcuffs were too tight...they just ignored it...they even tied my legs to the chairs [on the plane]...I was struggling to breathe, it was really horrible and one of the worse things that happened to me...I was crying, two of the members of security were swearing at me 'f**k you, $f^{* * k}$ your family'." (Ferhad)

Many participants outlined their emotional state on arrival in the UK, and described being low in mood, distressed, preoccupied with thoughts of death/dying, crying a lot and a profound sense of confusion and disconnection with their surroundings. 
"All the time I felt very low...I was telling myself, just stay strong, this is only temporary and soon it will be over. At that time I wished I was dying. When I was going to sleep I wished that I wouldn't wake up. "(Niki)

"When I first arrived I felt like a lot of other people do when they first arrive, I felt lost, I felt very confused...like I did not know where I am...that was...in the first couple of days and everyone is like that" (Lila)

Some participants described feeling a sense of loss of their former 'good lives', which now had to be re-built from scratch in under difficult circumstances. There was a sense of inevitability about this; as though there were no options to return home, given previous ties had now been severed.

"When you come here you feel like you have lost everything. You have left everything behind you. You have broken all of the bridges behind you and you don't have anywhere to go back...it makes you very worried" (Lila)

\section{Theme 3: 'Asylum Seeker' Identity in the UK}

This theme outlines the way in which three particular constructs / sub-themes ('the asylum system', 'the stress of resettlement' and 'coping') interact to create a unique identity for participants; as an 'asylum seeker in the $U K$ '. These constructs appeared to lead to a core dilemma for participants; primarily whether to attempt to return home, or try to seek safety elsewhere.

The Asylum System

Participants discussed the perpetual challenges they faced with the UK immigration system, and the ways this impacted on their economic, social and psychological wellbeing. As illustrated by Thomas and Siddiq, this was often conceptualised as 'a struggle', characterised by overtly-bureaucratic processes, which resulted in people experiencing the system as being at best depersonalising, and at worst, 'torturing' and re-traumatising, carrying particular poignancy and resonance given the previous traumatic events that participants had been exposed to in their country-of-origin.

"You have to submit yourself and then wait...It's a very depersonalized system... When you arrive, you are like handing yourself to them... they take you, then they put you in a place and you have to wait...this experience, is more tormenting...very torturing" (Thomas) 
"I turned up at 8 o clock and they gave me a number. And after 4 hours...they called me...[the interviewer] didn't ask me what was my problem, like why I had come here. She didn't ask me anything. Straightaway she said you can make an appointment and then you can come back. After 4 or 5 hours of waiting she said to me like that...with a small baby [with me]." (Siddiq)

Thomas goes on to talk about the label of being an 'asylum seeker', viewing this as a derogatory and insulting term which denotes a sense of inequality, entrapment and dependence on the system that was processing them.

"I could not accept to come here as an asylum seeker. You know it's very disrespectful for me...they put you in a kind of place and then you are dependent...You feel like an asylum seeker. It's like you, you are an asylum seeker. It's like an insult...you don't have the same rights as everybody else. So you are living like that" (Thomas)

Many participants expressed feeling of uncertainty around their asylum decision. The decision had significant implications for participants, including the possibility of being removed to country-of-origin, carrying with it the possibility of further persecution. As highlighted by Lila and Ahmad, the asylum decision had a significant impact on mental health;

'You don't feel safe, you don't know how long you are able to stay for, you don't know when your interview will be, you don't know whether you will get granted or not. So the feeling of being unsafe gets worse...If you get a negative [asylum] result, what will happen? This makes you worry... you feel unsafe. After the [asylum] interview, you try to carry on with your life...try to get yourself more relaxed. But every day it gets worse, because all of the memories come back from back home ... When you don't have a positive decision, you always feel in a 'storm'." (Lila)

"I am still not secure...Because they haven't accepted me staying here yet...I'm scared all the time that they will deport me back to [country of origin]. All the time, all the tortures, prisons, hanging, tying on the bed, lashings on the foot, that all comes back" (Ahmad)

All participants discussed financial, employment or living arrangement restrictions in regard to asylum status. Under immigration legislation, people seeking asylum are unable to gain paid employment, and for participants, employment is synonymous with improved financial security, opportunity for distraction, and means of integrating with host communities, and a feeling of making a contribution to society, some of which is illustrated here by Farah; "Work makes you busy during the day so you don't have time to think about what's happened. And when you get back home, you're tired so you sleep better... when you don't work, you're thinking all the time of what happened before again and I think you lose your day...if they can be useful...they don 't feel empty they feel like they are doing something here as well, this will give them pride...it makes you feel alive" (Farah)

Some participants, including Suri, highlighted provision of vouchers rather than money for shops, leading to further stigmatisation and isolation from the host community. 
"They said that with those vouchers you cannot have those sort of things... We were very upset. The other day we went to [supermarket] to just buy some bedsheets and they said you can't get those ones, you have to get the cheaper ones with the voucher." (Suri)

\section{The stress of resettlement}

When talking about adapting to life in the UK a number of participants, including Farah and Majid, discussed the way in which they felt disconnected, guilty and lonely as a result of separation from family and friends;

"When we were in our country we had our family around us and our people around us. Living here we are very lonely." (Farah)

"I feel very depressed, because I left all of my family behind me... an hour ago when I spoke to [my mother] to say happy new year to her, she was crying because I was absent from the family...she feels my absence. "(Majid)

Further, some suggested that coming to the UK and the variation in culture, family, values, and language left them feeling different, compounded by experienced hostility from some aspects of the communities into which they had moved;

"[I] can't even deal with your basic problems in this country because of the language barrier...For example, in the pharmacy, there is no interpreter there so you can't communicate...It causes me a lot of problems. The other day my daughter was ill...I had to go to the pharmacy and buy some medication myself. I did not know how to say that...They said...I had to go to A\&E. I don't even know where that hospital is. So I didn't know what to do." (Lila)

Practical situations, such as accessing medical, social and legal support were also identified as stressors, including Farah and Lila who described some of these challenges; "When we arrived, we went to [Hotel] and it was very bad, a dirty, very messy place... The accommodation agency knew about my husband's problem... He has a really bad back problem, so he couldn't walk up the stairs". (Farah)

"It is important for someone to explain the laws to us in this country. When we first arrive. Someone to tell us what to do in the Home Office. When other people have a problem with the council, no one knows anything about the law. We need some information about the laws in this country."(Lila)

All participants reported psychological effects of such experiences in re-settlement. These included feelings of fear (i.e. around removal), sleep problems, (e.g. nightmares) and fatigue, isolation, feelings of frustration, concentration difficulties, feeling overwhelmed, and feelings of disconnection from their emotional state. Some of these experiences are illustrated in this quote by Niki; 
"I am very scared, even of my own shadow...All the time I stay in my room...I sleep only with medication...I've got tablets to take, otherwise I cannot sleep. Every night I get nightmares that they are coming to arrest me...Usually I was very active [at home]. I am [young], but I feel very old and very tired."(Niki)

In attempting to cope with such experiences and intense emotions, some participants described talking to their GP and getting prescriptions for medication to help with mental health. Others, such as Ahmad, reported using self-harm as a means of coping with difficult emotions;

"During the night I fall down off the bed. [I] have loads of bad dreams, seeing lots of scary things. So it makes me anxious when I woke up and didn't feel like I had anyone to go to or talk to...I feel very scared inside myself, so sometimes I decide to burn myself to get rid of the feelings inside...so I can feel relief from all of this stress and anxiety." (Ahmad)

\section{Inner Strength}

It became apparent during interviews that terms such as 'coping' and 'resilience' had little resonance in the cultures that participants were from, nor languages spoken. The term that emerged that most appropriately described these phenomena was 'inner strength'.

Some participants, such as Lila and Suri, articulated the importance of religious beliefs in relation to this;

"I believe in God...god that gave me strength...any good things that happen in my life, any positive things, it's from God" (Lila)

"[going to church] Its very relaxing...it just makes me feel good and more relaxed and the people there are very nice and good to me."(Suri)

Other participants described drawing upon feelings of optimism and having a positive outlook on their situation (e.g. Thomas), as well as using distraction strategies and keeping busy as a way of managing stressful circumstances (e.g. Ferhad).

"Being positive, being optimistic...even though problems have occurred, you know that I will make it. I will come out, this is a good character for life. I am suffering, but positive" (Thomas)

"Those two days I go to college, it helps me a little, to not to think about what happened or what is going on. It can help, it can make my mind feel easier...Those two days go so fast, I don't think about the problems that I have got that much...I try to just make myself feel occupied...the main thing is about having something to do. (Ferhad)

Virtually all participants described the importance of family (either with them in the UK or overseas), friends and project workers in being able to manage their difficult situations. Here, 
Siddiq speaks about the importance of remaining strong to support his family, and Ahmad talks

about the support he receives from his mental health worker;

"I struggle, why? Because I don't only live for myself. I have to think about my wife. I have to think about my son. I have to make the easy life for my wife and my son...The man has to be brave...like an umbrella for the wife. Our culture is like that... [my wife] left her family as well. How can I leave her? How can I leave my baby? These things are making me strong." (Siddiq)

"[my Project worker] is like a sister for me and very helpful...When she is with me I feel safe...She talks to me...is kind to me ...When I see her I feel calmer and more secure...if [you have] somebody to trust, it's really important...I'm like a child now, who feels safe with the mum... [my project worker] is like that for me now. If I have any trouble or I'm scared, I go to her and she makes me feel better...She is like an angel." (Ahmad)

Linked to the support of others, as articulated by Ahmad, some participants noted the importance of being able to talk to other people about their situations and difficulties, describing this as being cathartic and necessary to help with their mental health;

"When we come [the] only person that you...see is the GP. But if you have a counsellor...that would be somebody who could be honest with us and we can talk about our problems and can help us. [Talking about emotions] can be very helpful" (Lila)

"If they can send someone...involved in mental health, to talk to them when they first arrive...it can be very useful emotionally...just to talk about what they have gone through. "(Farid)

The dilemma of returning home

The previously documented themes appeared in the data to culminate in a core dilemma for participants, principally, wanting to return to their home country in order to see family, and to try and re-establish their previous lives (though with the threat of the authority that had made it dangerous for them in the first place), versus staying in the UK (with security, but with the constant sense of disconnection from family and culture). This was classified in some participant narratives, as illustrated by Thomas and Saeed, as being a difference between a 'slow' and 'fast' death.

"I would like to be in my country...You were born in that country. You grew up in that country. Everything was in your country...But. I am obliged to leave...Because I want to save...my life...sometimes I say is the decision that I made bad or what...I could have been killed. I decided to leave. But I left my country to have a place where I can be free." (Thomas)

"It [dilemma of wanting to return] is the same for me...I would like to be in my country, because that is home, the place where all my relatives are...mixing with people here is very different. And difficult. So of course I want to go back, but can't because I am not safe there" (Saeed) 


\section{Theme 4: Reflections on the Future}

The interview data indicated that the first three themes clearly impacted upon the ways in which participants considered the future.

An ongoing sense of hope was linked by some participants with a desire to return home, but for others, this related to an aspiration to reconnect with family, whether in their country of origin, or in the UK. Participants remained hopeful about their asylum decision, despite the stress and difficulties of the system, and many wanted certainty around their status to be able to get back to 'living their life' as there was a feeling of lives being 'on hold' whilst waiting for a decision. Further, asylum status meant being able to go back to leading a more regular life (e.g. having paid employment). Some participants suggested that their hope was not around staying in the UK, but for circumstances to change back at home so they would be able to return to their culture and family.

"I just accept the situation... With hope, that one day things will be sorted...[to] be granted status, so I can bring my family here...bringing my children...and...family, here if I get granted"(Saeed)

"[Asylum decision means] you have the same rights as everybody, you can decide what I should now do... Hope means for me that one day, they will decide [about asylum]...the day they will decide, I will be free... if they give you a decision, it means you know you are free...now I am not free" (Thomas)

Linked to the concept of hope for the future, was a sense of having to be patient and wait for a positive decision and for circumstances to change. Many participants described the way that religious beliefs enabled them to feel hopeful and patient.

"I have to wait and have patient until God helps me...patience is one of the main things for my religion."(Lila)

"My beliefs, and when I see that I am still alive, I can still breath, I can still walk, I have hope for the future...Be patient, have a belief in God and have hope that everything will be ok."(Niki)

\section{Discussion}

The key aim of the study was to investigate experiences of the asylum journey, alongside methods of coping. To the knowledge of the authors, this was the first study to investigate this in 
this population, and the only study to use a CGT methodology to do so. Previous studies have addressed specific aspects of this journey but have routinely used mixed samples of forced migrants (asylum seekers and refugees). Given that seeking asylum status creates a particular set of circumstances (i.e. involvement in a complex system, subjecting people to limitations / restrictions, leaving people uncertain as to future residency status), this study particularly focussed on the meanings that participants made of their experiences and the ways in which they coped.

Given the structure of the interview schedule, it was anticipated that a temporal framework would emerge from the analysis, and this fit well with participant narratives around their experiences. Four key themes emerged from the data (Before Asylum; Displacement; 'Asylum seeker' identity in the UK; Reflections on the future), with experiences within each theme impacting upon the ways in which the subsequent theme / stage of the journey was conceptualised by participants.

\section{Before Asylum}

Participants discussed lifestyles prior to experiencing difficulty in their country of origin, which were characterised as being safe and secure, economically stable with regular employment and being surrounded by families and friends. This resonated with concepts outlined in attachment theory (e.g. Bowlby, 1984), where safety and interconnectedness with others are related concepts.

It was apparent that the concept of 'resilience' was unfamiliar for participants in this sample, as this concept did not translate into Farsi and had limited cultural-applicability. However, the phrase 'inner strength' was used and thus explored further, seemingly analogous in meaning to the concept of resilience. Data that emerged from interview transcripts was consistent with Bonanno's (2004) model of resilience, principally that it is commonplace to observe resilience in people who have been through adverse experiences (most participants described 
some form of inner strength), and that there are often multiple pathways (e.g. both supportive and challenging experiences) to developing resilience.

\section{Displacement}

Interview data supported the idea that participants underwent a shift from a position of safety and security in their country of origin to one of being in danger and having to leave. Participants described, in detail, traumatic events in country-of-origin, often at the hands of political or religious authorities, supporting findings from previous research that traumatic stress reactions are common in this client group (e.g. Neuner et al. 2004).

Participants described the importance of needing to talk about traumatic events they had experienced. Whilst participants were not asked about such experiences directly (given ethical concerns around limitations of therapeutic support) almost unanimously participants spoke about such events of their own accord. This supports the idea of a cathartic need to discuss such traumas (e.g. Pennebaker \& Beall, 1986; Stiles, 1987), and adds weight to the notion of needing someone to bear witness to traumatic events in order to heal (Herman, 1992).

Interview data resonated with the findings of Zimmerman (2009), which challenges the misleading suggestion that asylum seekers engage in 'asylum shopping' (choosing a country that offers the best conditions). This term is often used to stigmatise new arrivals in host countries. However, the data indicated that people had settled and comfortable lives in their home-countries prior to changing circumstances and a need for safety. In other words, for participants in this sample, 'push factors' such as dangerous circumstances in home countries, outweighed 'pull factors', such as improved financial/material circumstances in host countries (Schoorl et al., 2000).

In reflecting upon coping with traumatic events, participants talked about drawing on religion, companionship, inner strength and a search for safety. This supports and extends findings from previous research, indicating that social support and religious beliefs are important for resilience-development in forced migrants (Schweitzer et al., 2007; Kleinman, 1990). 


\section{'Asylum seeker' identity in the UK}

Some participants reported that progression through the asylum system was 'a struggle' and had a de-personalising effect and detrimental impact on self-esteem, supporting the findings of Gower et al. (2007), and Bogner et al. (2010). A key challenge faced by participants was the uncertainty of whether asylum status would be granted, and the possible impact of a refused application (e.g. potential removal from the UK), resonating with the findings of Rees (2003) who suggests faster processing of asylum claims due to the considerable stress such uncertainty can create.

Hussein et al. (2011) note that many forced migrants are willing to work, but legislation prevents it. Dwyer (2005) and Dwyer \& Brown (2005) suggest that there are continuously increasingly levels of governance and restriction on asylum seeker welfare. Gower et al. (2007) highlight that the asylum system creates welfare difficulties, limiting financial capacity, and that preventing people from working can be detrimental for psychological health and wellbeing. Participants in the current study explored numerous daily stressors around language, accommodation, lack of medical and legal support and isolation and these were clearly linked to psychological distress. Numerous studies have indicated that such post-migratory stressors can contribute to the development of mental health problems, indicating a need for policy changes in such areas, as well as a need for mental health services to consider the vast array of adaptation difficulties that asylum seekers face (e.g. Ellis et al., 2007; Bhugra \& Becker, 2005; Taloyan et al., 2011; Palmer \& Ward, 2006). Participants clearly articulated ongoing psychological distress, describing themselves as fatigued, threatened / frightened / scared, unable to concentrate, overwhelmed, detached from emotions, and experienced nightmares and sleep difficulties. Whilst no direct causal links with post-migratory factors can be demonstrated, participants indicated that their mental health difficulties were exacerbated by the stress caused by the asylum-seeking process.

Participants also described feeling disconnected from their communities and families and feeling rejected by UK communities. This is relevant given the trauma models presented by Herman (1992) and de Zulueta (2007) which suggest that a sense of connection with a community 
is essential for recovery from traumatic events. Participants highlighted times where they had experienced facing hostility from UK communities, supporting the findings of Pearce \& Charman (2011). This has implications for how asylum seekers who have survived trauma can adapt and make sense of their difficulties in a hostile community context.

Connection with others was a key aspect of coping, and supports studies which suggest improved outcomes in trauma survivors who have had social support compared to those who have not (Green et al., 1985), consistent with the trauma-recovery model presented by Herman (1992). The concerning alternative, however, is that hostile and negative responses from the community may predict a more aggravated traumatic response.

\section{Reflections on the future}

Participants hoped for circumstances to change in order that they could have a more connected life (with family and culture), either in their country of origin or in the UK (with family coming to the UK to stay with them). This again highlights the importance of relationships with others (Herman, 1992), though the concept of hope in relation to asylum seekers is scarce in the literature. In order to manage the uncertainty about their future, participants described a need to be patient, and suggested that religion and spirituality helped them in being able to do this.

\section{Service implications}

Mental health practitioners working with this population should consider narrative-based assessments, examining historical and current stressful events. Support provision would benefit from being co-produced and service-user informed (e.g. Strokosch \& Osborne, 2016), and jointworking / pathway-planning between statutory and third sectors could result in better outcomes for this population. Pathways to resilience / inner strength should be emphasised in support sessions, and practitioners delivering such support should be offered supervision, given the risk of vicarious traumatisation (Pearlman \& Mac Ian, 1995). Clinicans working with asylum seekers would benefit from having a more holistic understanding of the profound psychological experiences and impacts of the asylum system resulting from their journeys. 
Policy implications should target detention \& restrictions, as use of detention has concerningly been linked to pervasive psychological distress (Coffey et al., 2010). Further, the findings indicate that other issues, such as ability to work and provision of state support, can have a considerable impact upon psychological distress, and as such require consideration in the policymaking arena. There are important considerations for the UK Government Home Office, in regard to application processes. Uncertainty created around a lack of decision creates considerable distress and tension for asylum seekers requiring faster processing of claims, along with a more bespoke service (Bogner et al., 2010; Rees, 2003). The negative experiences of this population and the impact that this has had on subsequent adjustment and functions and use of health and social care resources has an impact on resultant contribution to host societies.

\section{Strengths \& limitations}

Whilst the study increases understanding of how asylum seekers conceptualise and cope with the asylum journey, it is important to note that such findings cannot be considered representative of asylum-seeking populations as a whole. There was considerable variance in the population in terms of length of time in the UK, country of origin, and reason for seeking asylum. It could be considered that this contributed to the diversity of the sample, as well as being representative of the asylum-seeking population in Wales. However, this renders the sample less-homogenous and caution is required when considering generalising our findings to other asylum-seeking populations. In addition, the sample was predominantly male (there were four females in the sample, as opposed to 7 males) and mostly Farsi-speaking people from the Middle-East as a result of limited resources to undertake the study, so in respect to gender and race, the sample may not be representative of the wider asylum seeking population. Further, given time-restrictions, triangulation with a focus group was not possible, though this may have been beneficial to allow participants to evaluate the extent to which the emergent theory resonated with their experiences.

\section{Conclusions}


To our knowledge this is the first study to investigate and describe the experiences and effects of the asylum seeker journey using a qualitative methodology. The study adds to the literature by demonstrating some of the profound psychological challenges of journey process for the individual through experiences of threat to life, escape, disconnection from family and the familiar. Our study shows that asylum seekers find the asylum process depersonalising, marginalising, stigmatising and sometimes retraumatising. It also demonstrated the challenges of becoming familiar with the host society culture and values; and of navigating unfamiliar medical, social and legal systems. Our study also demonstrates that asylum seekers have ways they manage and cope with these stressors, both internally (conceptualised as 'inner strength') and externally (e.g. support networks). Stress and resilience factors interact creating a dilemma for people as to whether to return to their country of origin. The findings lend support to community-focussed trauma models and concepts of resilience presented. Future research could examine these findings in wider samples of asylum seekers, to further investigate impacts that current policies have on ways in which asylum seekers cope with new lives in the UK and elsewhere. Further, study results could help inform the development of more focussed healthcare interventions for this often disadvantaged population. 


\section{REFERENCES}

Afuape, T. (2011). Power, Resistance and Liberation in Therapy with Survivors of Trauma: To Have Our Hearts Broken. Routledge: Taylor \& Francis Group.

Bhugra, D. \& Becker, M.A. (2005). Migration, Cultural Bereavements and Cultural Identity. World Psychiatry, 4(1), $18-24$.

Blinder, S. (2016). Briefing: Migration to the UK: Asylum. The Migration Laboratory at the University of Oxford, $5^{\text {th }}$ Revision.

Bogner, D., Brewin, C. \& Herlihy, J. (2010). Refugees' Experiences of Home Office Interviews: A Qualitative Study on the Disclosure of Sensitive Personal Information. Journal of Ethnic and Migration Studies, 36(3), 519-535.

Bonanno, G.A. (2004). Loss, Trauma, and Human Resilience: Have we Underestimated the Human Capacity to Thrive After Extremely Aversive Events. American Psychologist, 59(1), 20-28.

Bowlby, J. (1984). Attachment and Loss ( $2^{\text {nd }}$ Ed.). Hamondsworth: Penguin Books.

British Psychological Society (2009). Code of Ethics and Conduct. Leicester: British Psychological Society.

British Psychological Society (2011). Code of Human Research Ethics. Leicester: British Psychological Society.

Carey-Wood, J., Duke, K., Karn, V. \& Marshall T. (1995). The Settlement of Refugees in Britain. London: HMSO (Home Office Research Study 141).

Carswell, K., Blackburn, P. \& Barker, C. (2011). The Relationship Between Trauma, Post-Migration Problems and the Psychological Well-Being of Refugees and Asylum Seekers. International Journal of Social Psychiatry, 57: 107 DOI: $10.1177 / 0020764008105699$

Charmaz, K. (1995). Grounded theory. In J. Smith, R. Harre, \& L. Langenhove (Eds.), Rethinking Methods in Psychology, pp.27-65. London: Sage.

Charmaz, K. (2006). Constructing Grounded Theory: A Practical Guide Through Qualitative Analysis. London: Sage Publications.

Coffey, G.J., Kaplan, I., Sampson, R.C. \& Tucci, M.M. (2010). The Meaning and Mental Health Consequences of Long-Term Immigration Detention for People Seeking Asylum. Social Science \& Medicine, 70, 2070-2079.

Conlon, D. (2011). A Fractured Mosaic: Encounters with the Everyday Amongst Refugee and Asylum Seeker Women. Population, Space and Place, 17, 714-726.

Data Protection Act 1998 (1998). London: Stationary Office.

Dey, I. (1999). Grounding Grounded Theory: Guidelines for Qualitative Inquiry. San Diego: Academic Press.

De Zulueta, C.F. (2007). Mass Violence and Mental Health: Attachment and Trauma. International Review of Psychiatry, 19(3), 221-233.

Dwyer, P. (2005). Governance, Forced Migration and Welfare. Social Policy and Administration, 39(6), 622-639.

Dwyer, P. \& Brown, D. (2005). Meeting Basic Needs? Forced Migrants and Welfare. Social Policy and Society, 4, 369-380.

Elliot, R., Fischer, C.T. \& Rennie, D.L. (1999). Evolving Guidelines for Publication of Qualitative Research Studies in Psychology and Related Fields. British Journal of Clinical Psychology, 38, 215- 219.

Ellis H., Kia-Keating, M., Yusuf, S., Lincoln, A. \& Nur, A. (2007). Ethical Research in Refugee Communities and the use of Community Participatory Methods. Transcultural Psychiatry, 44, 459- 481.

Gower, M., Liisanantti, A., Dawkins, J. (2007). Asylum Rights Watch: Summary of Responses June-September 2007. Asylum Aid.

Green, B.L., Wilson, J.P. \& Lindy, J.D. (1985). "Conceptualising Post-traumatic Stress Disorder: A Psychosocial Framework". In C.R. Figley (Ed.) Trauma and Its Wake: The Study and Treatment of Post-Traumatic Stress Disorder (Vol.1). Taylor \& Francis Group. 
Herman, J.L. (1992). Trauma and Recovery: The Aftermath of Violence - from Domestic Abuse to Political Terror. Basic Books - A Division of HarperCollins Publishers.

Hoare, T., Vidgen, A. \& Roberts, N. (2017). In their own words: a synthesis of the qualitative research on the experiences of adults seeking asylum. A systematic review of qualitative findings in forced migration, Medicine, Conflict and Survival, 33:4, 273-298, DOI: 10.1080/13623699.2017.1419902

House of Commons Library (2019). Briefing Paper Number SN01403 Asylum Statistics. By Georgina Sturge. Accessed on 13/4/19 at www.parliament.uk/commons-library

Hussein, S., Mathorpe, J. \& Stevens, M. (2011). Exploring the Potential of Refugees and Asylum Seekers for Social Care Work in England: A Qualitative Study. Health and Social Care in the Community, 19(5), 468-475.

Kang, C., Tomkow, L. \& Farrington, R. (2019). Access to primary health care for asylum seekers and refugees: a qualitative study of service user experiences in the UK. British Journal of General Practice, DOI: https://doi.org/10.3999/bjgp19X701309.

Kleinman, S.B. (1990). Terror At Sea: Vietnamese Victims of Piracy. American Journal of Psychoanalysis, 50(4), 351-362.

Laban, C.J., Gernaat, H.B., Komproe, I.H., van der Tweel, I. \& De Jong, J.T.V.M. (2005). Postmigration living problems and common psychiatric disorders in Iraqi asylum seekers in the Netherlands. Journal of Nervous and Mental Diseases, 193, 825-832.

Lyons, K., Thone, E., Kirchgaessner, S., Baumard, M. \& Galarraga, N. (2017). Britain is one of the worst places in western Europe for asylum seekers. The Guardian [online] p.1. Available at: https://www.theguardian.com/uknews/2017/mar/01/britain-one-of-worst-places-western-europe-asylum-seekers [Accessed 25 Jun. 2017].

Marshall, G.N., Schell, T.L., Elliott, M.N., Berthold, S.M. \& Chun, C.A. (2005). Mental health of Cambodian refugees two decades after resettlement in the United States. JAMA: Journal of the American Medical Association, 294, 571-579.

Migration Watch UK (2006). The Distinction Between Asylum Seekers and Refugees. Briefing Paper 8.11.

Migration Watch UK (2017). Immigration System, Asylum \& Policy. Accessed on 13/4/19 at https://www.migrationwatchuk.org/key-topics/immigration-system

Mollica, R.F., McInnes, K., Poole, C. \& Tor, S. (1998). Dose-effect relationships of trauma to symptoms of depression and post-traumatic stress disorder among Cambodian survivors of mass violence. British Journal of Psychiatry, 173, 482-488.

Neuner, F., Schauer, M., Klaschik, C., Karunakara, U. \& Elbert, T. (2004). A Comparison of Narrative Exposure Therapy, Supportive Counselling and Psychoeducation for Treating Posttraumatic Stress Disorder in an African Refugee Settlement. Journal of Consulting and Clinical Psychology, 72 (4), 579-587.

Nissa, F. (2005). Public Attitudes to Asylum: Navigation Guide. London: ICAR.

O’Donnell, C.A., Higgins, M., Chauhan, R. \& Mullen, K. (2008). Asylum seekers' expectations of and trust in general practice: a qualitative study. British Journal of General Practice, DOI: 10.3399/bjgp08X376104.

Onyut, L.P., Neuner, F., Ertl, V., Schauer, E., Odenwald, M. \& Elbert, T. (2009). Trauma, Poverty and Mental Health Among Somali and Rwandese Refugees Living in an African Refugee Settlement - an Epidemiological Study. Conflict and Health, 3(6).

O’Sullivan-Lago, R. \& de Abreu, G. (2010). The Dialogical Self in a Cultural Contact Zone: Exploring the Perceived 'Cultural Correction' Function of Schooling. Journal of Community \& Applied Social Psychology, 20, 275-287.

O’Sullivan-Lago, R., de Abreu, G. \& Burgess, M. (2008). 'I am a Human Being like You': An Identification Strategy to Maintain Continuity in a Cultural Contact Zone. Human Development, 51, 349-367.

Palmer, D. \& Ward, K. (2006). 'Unheard Voices': Listening to Refugees and Asylum Seekers in the Planning and Delivery of Mental Health Service Provision in London: A Research Audit on Mental Health Needs and Mental Health Provision for Refugees and Asylum Seekers Undertaken for the Commission for Public Patient Involvement on Health (CPPHI). Shaping Health: Better Decisions, Better Health.

Palmer, D. \& Ward, K. (2007). “'Lost': Listening to the Voices and Mental Health Needs of Forced Migrants in London." Medicine, Conflict and Survival 23 (3): 198-212. 
Pearce, J.M. \& Charman, E. (2011). A Social Psychological Approach to Understanding Moral Panic. Crime, Media, Culture, 7(3), 293-311.

Pearlman, L.A. \& Mac Ian, P.S. (1995). Vicarious traumatization: An empirical study of the effects of trauma work on trauma therapists. Professional Psychology: Research and Practice, 26(6), 558.

Pennebaker, J.W. \& Beall, S.K. (1986). Confronting a traumatic event: toward an understanding of inhibition and disease. Journal of Abnormal Psychology, 95(3), 274.

Priebe, S., Giacco, D. \& El-Nagib, R. (2016). Public health aspects of mental health among migrants and refugees: a review of the evidence on mental health care for refugees, asylum seekers and irregular migrants in the WHO European Region. Health Evidence Network Synthesis Report 47, World Health Organisation

Rees, S. (2003). Refuge or Re-trauma? The Impact of Asylum Seeker Status on the Wellbeing of East Timorese Women Asylum Seekers Residing in the Australian Community. Australasian Psychiatry, 11, 96-101.

Refugee and Asylum Seeker Voice (2017). The Waiting Game: The impact of delayed asylum decisions. Accessed on [27/1/19]. Available at https://www.refugee-action.org.uk/wp-content/uploads/2018/03/Refugee-and-AsylumSeeker-Voice-The-Waiting-Game-Report-1.pdf

Renner, W. \& Salem, I. (2009). Post-Traumatic Stress in Asylum Seekers and Refugees From Chechnya, Afghanistan, and West Africa: Gender Differences in Symptomatology and Coping. International Journal of Social Psychiatry, 55(2), 99-108.

Rugunanan, P. \& Smit, R. (2011). Seeking Refuge in South Africa: Challenges Facing a Group of Congolese and Burundian Refugees. Development Southern Africa, 28(5), 705-718.

Schoorl, J., Heering, L., Esveldt I., Groenewold, G. \& Van der Erf, R. (2000). Push and pull factors of international migration: a comparative report. Luxembourg European Communities Office for Official Publications, 2000.

Schweitzer, R., Greenslade, J.H. \& Kagee, A. (2007). Coping and Resilience in Refugees From the Sudan: A Narrative Account. Australian and New Zealand Journal of Psychiatry, 41 (3), 282-288.

Silove, D., Sinnerbrink, I., Field, A., Manicavasagar, V. \& Steel, Z. (1997). Anxiety, depression and PTSD in asylum- seekers: associations with pre-migration trauma and post-migration stressors. British Journal of Psychiatry, $170,351-357$.

Steel, Z., Silove, D., Bird, K., McGorry, P. \& Mohan, P. (1999) Pathways from war trauma to posttraumatic stress symptoms among Tamil asylum seekers, refugees, and immigrants. Journal of Traumatic Stress, 12, 421-435.

Steel, Z., Silove, D., Brooks, R., Momartin, S., Alzuhairi, B. \& Susljik, I. (2006) Impact of immigration detention and temporary protection on the mental health of refugees. British Journal of Psychiatry, 188, 58-64.

Stewart, E. (2005). Exploring the Vulnerability of Asylum Seekers in the UK. Population, Space and Place, 11, 499512.

Stiles, W.B. (1987). I have to talk to somebody. Self-disclosure, 257-282.

Strokosch and Osbourne, (2016). Asylum Seekers and the Co-production of Public Services: Understanding the Implications for Social Inclusion and Citizenship. Journal of Social Policy, 45(4), 673-690. doi:10.1017/S0047279416000258

Summerfield, D. (2001). The Invention of Post-Traumatic Stress Disorder and the Social Usefulness of a Psychiatric Category. British Medical Journal, 322, 95-98.

Tong, A., Sainsbury, P. \& Craig, J. (2007). Consolidated criteria for reporting qualitative research (COREQ): A 32 item checklist for interviews and focus groups. International Journal for Quality in Health Care, 19 (6), 349-357.

Taloyan, M., Ahmed, A., Johansson, L.M. \& Saleh-Stattin, N. (2011). Kurdish Men's Experiences of MigrationRelated Mental Health Issues. Primary Health Care Research and Development, 12, 335- 347.

Taylor, R. (2018). Impact of 'Hostile Environment' Policy Debate on 14 June 2018. UK House of Lords: Library Briefing.

UK Government: The Immigration Act (2014). Accessed on 25/1/2018 via http://www.legislation.gov.uk/ukpga/2014/22/contents/enacted 
UK Government: The Immigration Act (2016). Accessed on 25/1/2018 via

http://www.legislation.gov.uk/ukpga/2016/19/contents/enacted

United Nations High Commissioner for Refugees (1951). Convention Relating to the Status of Refugees (including text of 1967 protocol). Accessed on 23/5/13: http://www.unhcr.org/PROTECT/protection/3b66c2aa10.pdf

Van de Veer, G. (1998). Counselling and Therapy with Refugees and Victims of Trauma. 2nd ed. Chichester. Wiley.

Vincent, F., Jenkins, H., Larkin, M. \& Clohessy, S. (2012). Asylum-Seekers' Experiences of Trauma-Focussed Cognitive Behaviour Therapy for Post-Traumatic Stress Disorder: A Qualitative Study. Behavioural and Cognitive Psychotherapy, 41, 579-593.

Whittaker, S., Hardy, G., Lewis, K. \& Buchan, L. (2005). An Exploration of Psychological Well- Being with Young Somali Refugee and Asylum-seeker Women. Clinical Child Psychology and Psychiatry, 10, 177-196.

Willig, C. (2008). Introducing Qualitative Research in Psychology: Adventures in Theory and Method (2nd ed.). Berkshire: Open University Press.

Ziersch, A., Walsh, M., Due, C. \& Duivesteyn, E. (2017). Exploring the Relationship between Housing and Health for Refugees and Asylum Seekers in South Australia: A Qualitative Study. International Journal of Environment Research and Public Health, 14, 1036.

Zimmerman, S. (2009). Why Seek Asylum? The Roles of Integration and Financial Support. International Migration, 48(1), 199-231. 
Table 1: Characteristics of Sample Interviewed

\begin{tabular}{|c|c|c|c|c|c|c|c|c|}
\hline $\begin{array}{c}\text { Interview } \\
\text { Number }\end{array}$ & Name & $\begin{array}{c}\text { Age } \\
\text { Range }\end{array}$ & Gender & $\begin{array}{c}\text { Time in } \\
\text { UK }\end{array}$ & First Language & $\begin{array}{c}\text { Country of } \\
\text { Origin }\end{array}$ & Asylum Status & Reason for Seeking Asylum \\
\hline 1 & Ahmad & $41-65$ & Male & $1-5$ years & Farsi & Middle East & Seeking Asylum & Political Persecution \\
\hline 2 & Farah & $41-65$ & Female & $1-5$ years & Farsi & Middle East & Seeking Asylum & Political persecution \\
\hline 3 & Farid & $18-30$ & Male & $0-1$ year & Farsi & Middle East & Seeking Asylum & Religious Persecution \\
\hline 4 & Suri & $18-30$ & Female & $1-5$ years & Farsi & Middle East & Seeking Asylum & Political persecution \\
\hline 5 & Niki & $18-30$ & Female & $0-1$ year & Farsi & Middle East & Seeking Asylum & Political Persecution \\
\hline 6 & Siddiq & $31-40$ & Male & $1-5$ years & Urdu $^{2}$ & Southern Asia & Seeking Asylum & Religious \& Family Persecution \\
\hline 7 & Majid & $41-65$ & Male & $0-1$ year & Farsi & Middle East & Refugee Status & Political Persecution \\
\hline 8 & Thomas & $31-40$ & Male & $0-1$ year & French & Central Africa & Seeking Asylum & Political Persecution \\
\hline 9 & Ferhad & $18-30$ & Male & $0-1$ year & Farsi & Middle East & Seeking Asylum & Political Persecution \\
\hline 10 & Saeed & $41-65$ & Male & $5+$ years & Farsi & Middle East & Seeking Asylum & Religious Persecution \\
\hline 11 & Lila & $18-30$ & Female & $1-5$ years & Farsi & Middle East & Seeking Asylum & Family Difficulties \\
\hline
\end{tabular}

${ }^{1}$ This participant had two interviews due to time available. However, he was granted status between interviews. Data from his interview is included in the analysis.

${ }^{2}$ Interviews conducted in English 
Figure 1: A Constructivist Grounded Theory of how asylum seekers understand and cope with the asylum journey and process.

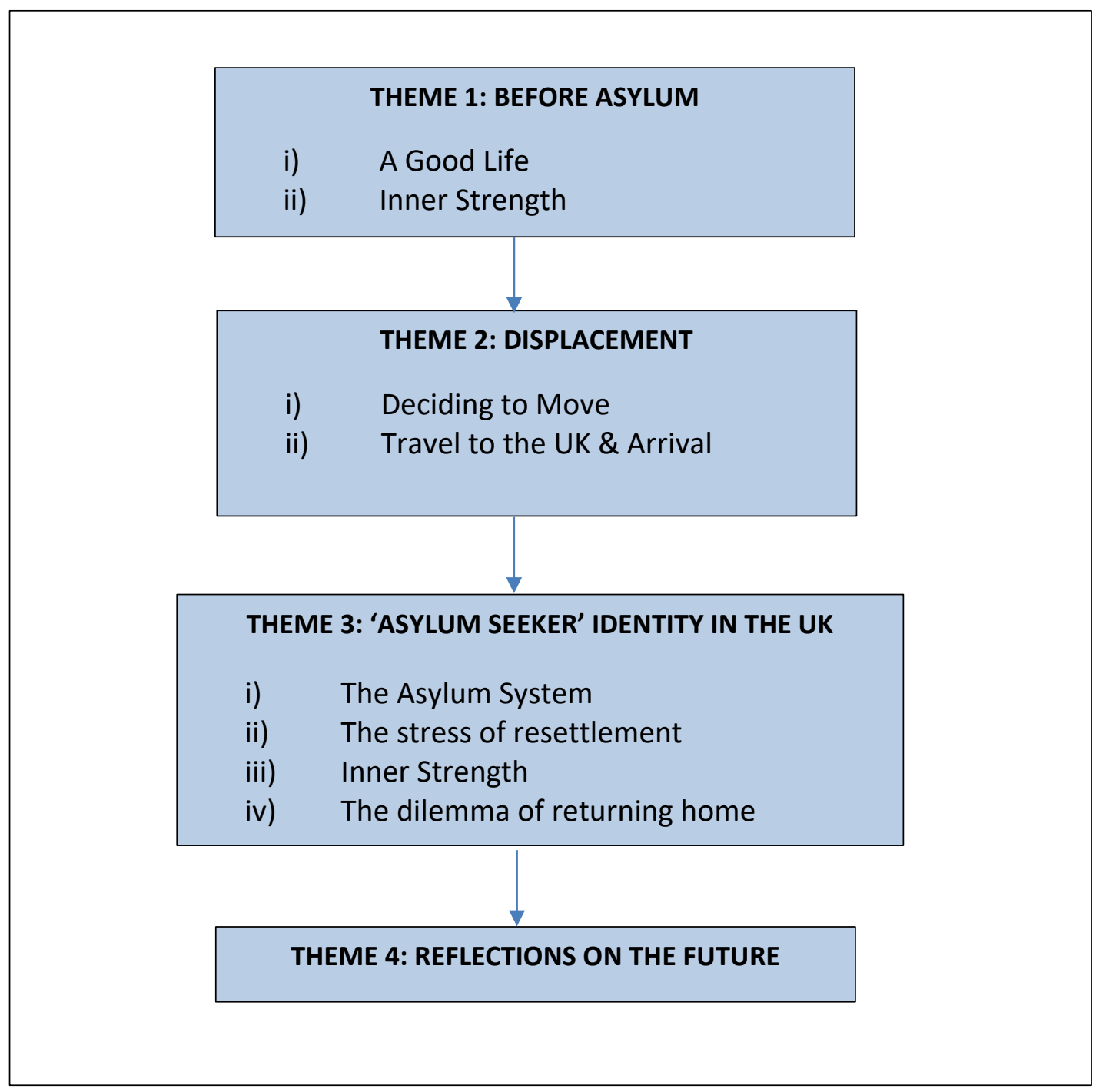

